\title{
Environmental and dietary factors to be checked for treatment of atopic dermatitis in rural children
}

\section{To the editor,}

Atopic dermatitis (AD) is a chronic inflammatory skin disorder, and treatment guidelines for $\mathrm{AD}$ emphasize identifying and avoiding exacerbating factors and practicing proper skincare. ${ }^{1)}$ Gangwon is a representative rural region of South Korea and has a pollen distribution pattern different from those of other regions. ${ }^{2)}$ Therefore, different patterns of immunoglobulin $\mathrm{E}$ (IgE) sensitization to food and aeroallergens may be observed owing to cross-antigenicity. ${ }^{3)}$ However, no studies have identified the distinctive characteristics of children with $\mathrm{AD}$ in this region. Thus, this study was conducted to identify factors to be focused on while treating children with $\mathrm{AD}$ living in rural areas.

We developed a standardized form for outpatient medical charts for the children newly diagnosed with $\mathrm{AD}$ by a pediatric allergist, consisting of 6 factors: (1) feeding method and weaning diet; (2) comorbidities (patient-oriented, doctor-diagnosed); (3) familial allergic disease history; (4) indoor environmental management including history of direct (currently living with a pet) or indirect (intermittent exposure when visiting relatives) exposure to pets; (5) dietary restriction and reasons for these; and (6) skincare practices. Severity was assessed based on the percent body surface area affected by $\mathrm{AD}^{4}{ }^{4}$ and serologic testing was generally recommended for moderate to severe AD. Sensitization was defined as the detection of allergen-specific IgE at levels $\geq 0.7 \mathrm{kU} / \mathrm{L}$ by ImmunoCAP (Thermo Fisher Scientific, Phadia AB, Uppsala, Sweden) or a result of class $\geq 2$ on the multiple allergen simultaneous test (MAST) (AdvanSure Allostation, LG Life Science, Seoul, Korea). . $^{\text {) }}$

The study population included 114 boys (59.7\%) and 77 girls (40.3\%) with a median age of 34 months (1 month to 18 years), and 105 (55.0\%), 66 (34.6\%), and 20 patients (10.5\%) had mild, moderate, and severe $\mathrm{AD}$, respectively. Among the 117 patients (61.3\%) who underwent serological testing, ImmunoCAP was performed in 101 patients ( $86.3 \%$ vs. MAST $63.2 \%$ [74 of 117]), the IgE sensitization rate to aeroallergen was $65.7 \%$ (46 of 70 vs. MAST $56.1 \%$ [32 of 57]) and the highest sensitization rate was observed for Dermatophagoides farinae (Der. f, 76.1\% [35 of 46]), followed by Dermatophagoides pteronyssinus (Der. p, 69.6\% [32 of 46]), birch (32.6\%, 15 of $46)$, dog dander $(32.6 \%, 15$ of 46$)$, and cat dander $(19.6 \%, 9$ of 46). These results differed slightly from the MAST results: Der. $f$
Table 1. Clinical and demographic characteristics of subjects

\begin{tabular}{|c|c|}
\hline Characteristic & Value \\
\hline \multicolumn{2}{|l|}{ Sex } \\
\hline Male & $114(59.7)$ \\
\hline Female & $77(40.3)$ \\
\hline Median age (mo) & $34(1-225)$ \\
\hline \multicolumn{2}{|c|}{ Severity of atopic dermatitis ${ }^{a)}$ according to age group } \\
\hline$<2 \mathrm{yr}$ & $76(39.8)$ \\
\hline Mild & $46(60.5)$ \\
\hline Moderate & $24(31.6)$ \\
\hline Severe & $6(7.9)$ \\
\hline $2-6 \mathrm{yr}$ & $65(34.0)$ \\
\hline Mild & $36(55.4)$ \\
\hline Moderate & $22(33.8)$ \\
\hline Severe & $7(10.8)$ \\
\hline $6-12 y r$ & $36(18.8)$ \\
\hline Mild & $19(52.8)$ \\
\hline Moderate & $14(38.9)$ \\
\hline Severe & $3(8.3)$ \\
\hline$>12 \mathrm{yr}$ & $14(7.3)$ \\
\hline Mild & $4(28.6)$ \\
\hline Moderate & $6(42.9)$ \\
\hline Severe & $4(28.6)$ \\
\hline \multicolumn{2}{|l|}{ Feeding } \\
\hline Exclusive breastfeeding for 4 mo & $84(44.0)$ \\
\hline Weaning diet after 6 mo & $139(72.8)$ \\
\hline \multicolumn{2}{|l|}{ Comorbidity } \\
\hline \multicolumn{2}{|l|}{ Patient-oriented } \\
\hline Allergic respiratory disease ${ }^{b)}$ & $86(45.0)$ \\
\hline Food allergy & $83(43.5)$ \\
\hline Anaphylaxis & $5(2.6)$ \\
\hline \multicolumn{2}{|l|}{ Doctor-diagnosed } \\
\hline Allergic respiratory disease ${ }^{b)}$ & $55(28.8)$ \\
\hline Food allergy & $38(19.9)$ \\
\hline Anaphylaxis & $5(2.6)$ \\
\hline \multicolumn{2}{|l|}{ Familial history of allergic disease } \\
\hline Allergic respiratory disease ${ }^{\mathrm{b})}$ & $112(58.6)$ \\
\hline Atopic dermatitis & $68(35.6)$ \\
\hline Food allergy & $37(19.4)$ \\
\hline
\end{tabular}

Corresponding author: Jeongmin Lee, MD, PhD. Department of Pediatrics, Yonsei University Wonju College of Medicine, 20 Ilsan-ro, Wonju 26426, Korea 凶 Email: ejeongmin@yonsei.ac.kr, https://orcid.org/0000-0002-1672-7445

Received: 6 May, 2021, Revised: 25 August, 2021, Accepted: 7 September, 2021

This is an open-access article distributed under the terms of the Creative Commons Attribution Non-Commercial License (http://creativecommons.org/licenses/by$\mathrm{nc} / 4.0 /$ ) which permits unrestricted non-commercial use, distribution, and reproduction in any medium, provided the original work is properly cited.

Copyright (c) 2021 by The Korean Pediatric Society 
(65.6\%, 21 of 32), Der. p (62.5\%, 20 of 32), house dust (46.9\%, 15 of 32$)$, birch (31.3\%, 10 of 32), dog dander (31.3\%, 10 of 32$)$, and cat dander (31.3\%, 10 of 32$)$. Among all subjects, 35.1\% (67 of 191) have documented the way of pet exposure (dog: $85.6 \%$ [58 of 67], direct $36.2 \%$ [21 of 58]; cat: 20.9\% [14 of 67], direct $57.1 \%$ [8 of 14]). Among them, sensitization rate to dog dander was $20.7 \%$ (12 of 58 ; direct 6 of 21 and indirect 6 of 37 ) and to cat was $7.1 \%$ ( 1 of 14 ; indirect 1$)$. The IgE sensitization rate to food was $50.0 \%$ by ImmunoCAP ( 39 of 78 ; egg white 29 , cow's milk 16 , peanut 14 , wheat 13 , soybean 9 , walnut 6 ) and $58.6 \%$ by MAST ( 17 of 29 ; egg white 12 , peanut 7 , wheat 7 , soybean 6 , apple 6 , peach 5 , walnut 5 , cow's milk 3 ). The IgE sensitization (aeroallergen: mild 32.4\% [ 34 of 105] vs. moderate 39.4\% [26 of 66 ] vs. severe $45.0 \%$ [ 9 of 20], $P=0.147$, food: mild $21.0 \%$ [22 of 105] vs. moderate $30.3 \%$ [20 of 66], severe $45.0 \%$ [9 of 20], $P=0.013$ ) rate increased with disease severity. In total, $44.0 \%$ children (84 of 191) were exclusively breastfed for the first 4 months after birth, and $72.8 \%$ (139 of 191) had started the weaning process from 6 months after birth. Patient-oriented and doctor-diagnosed food allergy accounted for $43.5 \%$ (83 of 191) and 19.9\% (38 of 191) of cases, respectively (Table 1). Sixty-eight patients $(35.6 \%=68 / 191)$ were fed a restricted diet. A doctor's recommendation was the most common reason for dietary restrictions (58.8\% [ 40 of 68 ]; egg white 24 , peanut 14 , cow's milk 11, walnut 9), followed by self-judgment (39.7\% [27 of 68]) with subjective allergic symptoms without medical evaluation (55.6\% [15 of 27]; egg white 6, cow's milk 5, wheat 5, soybean 4) and self-judgment without any symptoms and without medical evaluation (44.4\% [12 of 27]; egg white 3, peanut 2, wheat 2, cow's milk 1). One patient has refused to try and been restricted peanut and other tree nuts. Serologic testing was performed in $91.2 \%$ of patients (62 of 68 ) with dietary restrictions, and more than half (58.1\% [36 of 62]) tested positive for allergen-specific $\operatorname{IgE}$ (Fig. 1). IgE sensitization to egg white (65.6\% [21 of 32]) or cow's milk (64.7\% [11 of 17]) was more common than that to peanuts (36.8\% [7 of 19]) or walnuts (36.4\% [4 of 11]), and a clinical correlation was frequently observed. When the cutoff for testing positive for allergen-specific IgE was readjusted (ImmunoCAP $\geq 0.35 \mathrm{kU} / \mathrm{L}$ or MAST $\geq$ Class 1 , showing lower specificity and positive predictive value ${ }^{5)}$ ), the overall sensitization rate was $67.7 \%$ (42 of 62). Approximately half of the patients (59.2\% [113 of 191]) moisturized more than 3 times daily, and showered every day (66.5\% [127 of 191]), whereas $23.6 \%$ (45 of 191) took an approximately 10 -minute soak bath.

With the increasing prevalence of pediatric $\mathrm{AD}$, the importance of disease prevention, management, and identification of risk factors at an early age is being emphasized. Differences in comorbidities suspected by parents versus those diagnosed by a doctor were observed in this study, and in particular, food allergies were arbitrarily diagnosed by guardians. These results not only indicate that many subjects are unnecessarily prescribed dietary restrictions but also suggest the need for more active intervention as the frequency of this issue was higher than that in a previous studies. ${ }^{6}$ Particularly, although many of our subjects had not eaten walnuts or peanuts at this young age, they tended to be prescribed to avoid these foods without supportive clinical evidence. The rate of exclusive breastfeeding until 4 months was similar to that in the entire Korean population, ${ }^{7)}$ but the higher rate of late weaning, which is disadvantageous for $\mathrm{AD}$ prevention, ${ }^{8}$ demonstrated the need for evidence-based dietary intervention. The rate of sensitization to peanuts, birch, and dog dander were relatively higher than those reported in urban areas. ${ }^{9)}$ The Gangwon region has a higher tree pollen concentration than other regions ${ }^{2)}$ and is a major peaches producer, ${ }^{10)}$ possible resulting in peach and

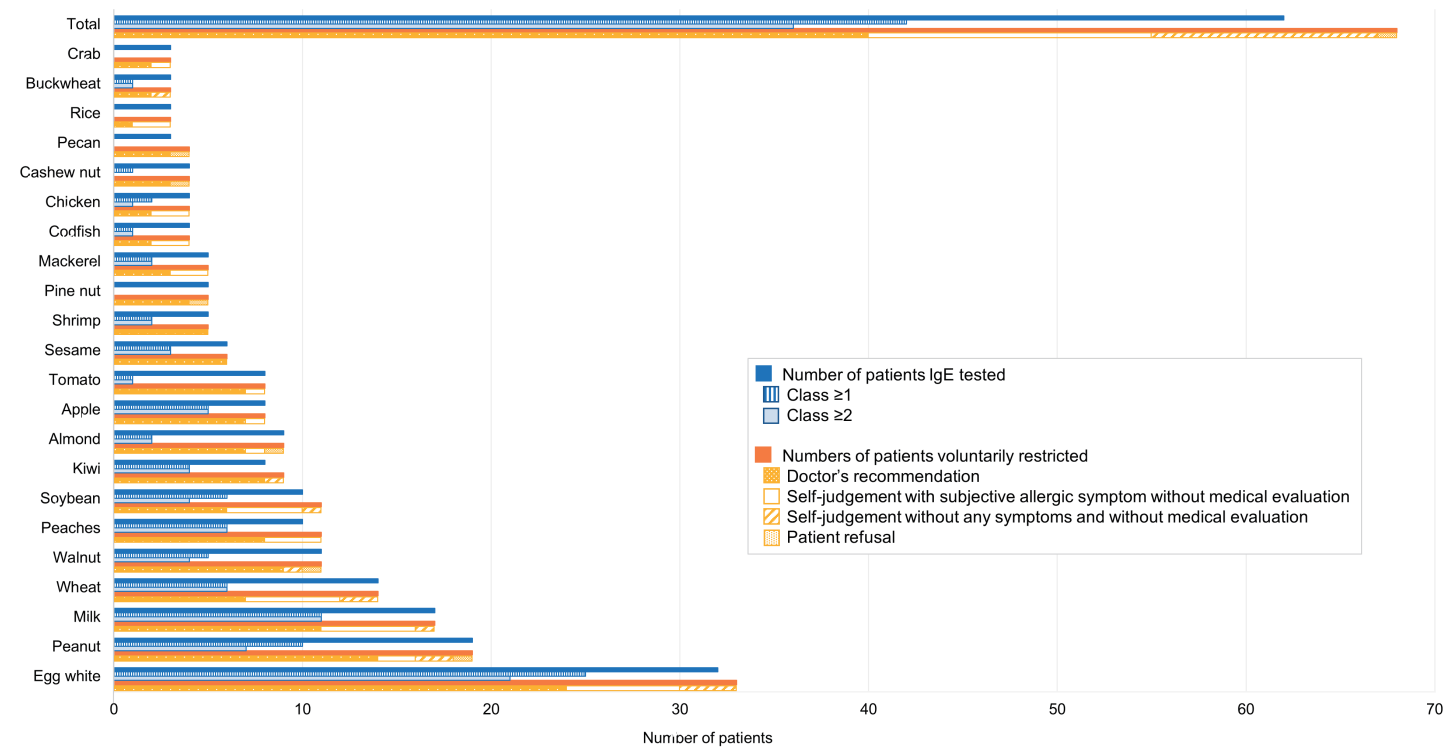

Fig. 1. Causes and immunoglobulin E ( $\mathrm{g} \mathrm{g}$ ) sensitization rates by causative food group in patients with dietary restrictions. Sensitization was defined as follows: class 1, allergen-specific IgE $\geq 0.35 \mathrm{kU} / \mathrm{L}$ by ImmunoCAP (Thermo Fisher Scientific, Phadia $A B$, Uppsala, Sweden) or class $\geq 1$ by the multiple allergen simultaneous test (MAST) (AdvanSure Allostation, LG Life Science, Seoul, Korea); class 2, $\geq 0.70 \mathrm{kU} / \mathrm{L}$ by ImmuoCAP or class $\geq 2$ by MAST. 
birch sensitization in many patients, which is rarely seen in urban areas. ${ }^{9)}$ For children with intermittent exposure to pets are in the risk of sensitization, whether the exposure occurs via relatives or other public places should be checked. For proper management of $\mathrm{AD}$ in rural children, the effect of dense pollen concentrations and indirect exposure to animals must be understood and evaluated. Evidence-based dietary restrictions should be implemented, and active bathing, especially for the management of acute flares, and proper moisturization ${ }^{1)}$ need to be constantly educated.

The study protocol was approved by the Institutional Review Board (IRB) of the Wonju Severance Christian Hospital (IRB no. CR-320110).

\section{Key message}

Question: What are the distinctive features of rural children with atopic dermatitis?

Finding: Birch and dog dander were the second most sensitized aeroallergens (32.6\%), followed by house dust mites. Doctors and guardians reported food allergy comorbidities differently (19.9\% and 43.5\%, respectively). Dietary restrictions without medical evaluation were observed in $39.7 \%$ of patients.

Meaning: Effects of pollen distribution and indirect animal exposure should be evaluated. Evidence-based dietary restrictions must be implemented.

Sanghwa Youm, $\mathrm{MD}^{1}$, Eunjoo Lee, $\mathrm{MD}^{2}$, Jeongmin Lee, MD, $\mathrm{PhD}^{1}$

${ }^{1}$ Department of Pediatrics, Yonsei University Wonju College of Medicine, Wonju, Korea; ${ }^{2}$ Department of Pediatrics, Inje University Busan Paik Hospital, Busan, Korea

\section{Footnotes}

Conflicts of interest: No potential conflict of interest relevant to this article was reported.
ORCID:

Sanghwa Youm (D) https://orcid.org/0000-0002-3555-7787

Eunjoo Lee (D) https://orcid.org/0000-0002-5351-5476

Jeongmin Lee (1) https://orcid.org/0000-0002-1672-7445

\section{References}

1. Wollenberg A, Barbarot S, Bieber T, Christen-Zaech S, Deleuran M, Fink-Wagner A, et al. Consensus-based European guidelines for treatment of atopic eczema (atopic dermatitis) in adults and children: part I. J Eur Acad Dermatol Venereol 2018;32:657-82.

2. Shin JY, Han MJ, Cho C, Kim KR, Ha JC, Oh JW. Allergenic pollen calendar in Korea based on probability distribution models and up-todate observations. Allergy Asthma Immunol Res 2020;12:259-73.

3. Asero R, Tripodi S, Dondi A, Businco ADR, Sfika I, Bianchi A, et al. Prevalence and clinical relevance of IgE sensitization to profilin in childhood: a multicenter study. Int Arch Allergy Immunol 2015;168:2531.

4. Chopra R, Vakharia PP, Sacotte R, Patel N, Immaneni S, White T, et al. Severity strata for Eczema Area and Severity Index (EASI), modified EASI, Scoring Atopic Dermatitis (SCORAD), objective SCORAD, Atopic Dermatitis Severity Index and body surface area in adolescents and adults with atopic dermatitis. Br J Dermatol 2017;177:1316-21.

5. Park DS, Cho JH, Lee KE, Ko S, Kim HR, Choi SI, et al. Detection rate of allergen-specific IgE by multiple antigen simultaneous testimmunoblot assay. Korean J Lab Med 2004;24:131-8.

6. Lee ES, Kim KS. Parental burden of food-allergic children's parents and influencing factors. J Nutr Health 2018;51:140-52.

7. Chung SH, Kim HR, Choi YS, Bae CW. Trends of breastfeeding rate in Korea (1994-2012): comparison with OECD and other countries. J Korean Med Sci 2013;28:1573-80.

8. Kim YH, Lee SG, Kim SH, Song YJ, Chung JY, Park MJ. Nutritional status of Korean toddlers: from the Korean National Health and Nutrition Examination Survey 2007-2009. Pediatr Gastroenterol Hepatol Nutr 2010;14:161-70.

9. Na MS, Kim GR, Ha EK, Lee SJ, Sheen YH, Choi SH, et al. Allergen sensitization and clinical characteristics in young children with atopic dermatitis. Allergy Asthma Respir Dis 2017;5:128-34.

10. Cho JG, Kim SH, Choi IM, Yun SK, Han JH, Oh PK. Changes pattern of peach cultivation areas for various location of Korea using statistical data. Korean J Horti Sci 2010;28:120.

How to cite this article: Youm S, Lee E, Lee J. Environmental and dietary factors to be checked for treatment of atopic dermatitis in rural children. Clin Exp Pediatr 2021;64:661-3 https://doi.org/10.3345/cep.2021.00605 